\title{
HIV patients treated with low-dose prednisolone exhibit lower immune activation than untreated patients
}

\author{
Christa Kasang ${ }^{1}$, Albrecht Ulmer ${ }^{2}$, Norbert Donhauser ${ }^{3}$, Barbara Schmidt ${ }^{3}$, August Stich ${ }^{4}$, Hartwig Klinker ${ }^{5}$, \\ Samuel Kalluvya ${ }^{6}$, Eleni Koutsilieri ${ }^{1}$, Axel Rethwilm ${ }^{1}$ and Carsten Scheller ${ }^{1 *}$
}

\begin{abstract}
Background: HIV-associated general immune activation is a strong predictor for HIV disease progression, suggesting that chronic immune activation may drive HIV pathogenesis. Consequently, immunomodulating agents may decelerate HIV disease progression.

Methods: In an observational study, we determined immune activation in HIV patients receiving low-dose (5 mg/ day) prednisolone with or without highly-active antiretroviral therapy (HAART) compared to patients without prednisolone treatment. Lymphocyte activation was determined by flow cytometry detecting expression of CD38 on CD8(+) T cells. The monocyte activation markers SCD14 and LPS binding protein (LBP) as well as inflammation markers soluble urokinase plasminogen activated receptor (sUPAR) and SCD40L were determined from plasma by ELISA.

Results: CD38-expression on CD8+ T lymphocytes was significantly lower in prednisolone-treated patients compared to untreated patients (median 55.40\% [percentile range 48.76-67.70] versus 73.34\% [65.21-78.92], $p=$ 0.0011, Mann-Whitney test). Similarly, we detected lower levels of sCD14 $(3.6 \mu \mathrm{g} / \mathrm{ml}$ [2.78-5.12] vs. $6.11 \mu \mathrm{g} / \mathrm{ml}[4.58-$ 7.70]; $p=0.0048), \operatorname{LBP}(2.18 \mathrm{ng} / \mathrm{ml}[1.59-2.87]$ vs. $3.45 \mathrm{ng} / \mathrm{ml}$ [1.84-5.03]; $p=0.0386)$, suPAR antigen $(2.17 \mu \mathrm{g} / \mathrm{ml}$ [1.65-2.81] vs. $2.56 \mu \mathrm{g} / \mathrm{ml}$ [2.24-4.26]; $p=0.0351)$ and a trend towards lower levels of sCD40L $(2.70 \mathrm{pg} / \mathrm{ml}$ [1.90-4.00] vs. $3.60 \mathrm{pg} / \mathrm{ml}[2.95-5.30] ; p=0.0782)$. Viral load in both groups was similar $\left(0.8 \times 10^{5} \mathrm{ng} / \mathrm{ml}\left[0.2-42.4 \times 10^{5}\right]\right.$ vs. 1.1 $\left.\times 10^{5}\left[0.5-12.2 \times 10^{5}\right] ; p=0.3806\right)$. No effects attributable to prednisolone were observed when patients receiving HAART in combination with prednisolone were compared to patients who received HAART alone.

Conclusions: Patients treated with low-dose prednisolone display significantly lower general immune activation than untreated patients. Further longitudinal studies are required to assess whether treatment with low-dose prednisolone translates into differences in HIV disease progression.
\end{abstract}

\section{Background}

Progressive depletion of helper $\mathrm{T}$ cells is a hallmark of untreated HIV infection. There is accumulating evidence that chronic immune activation may be a fundamental driving force of this T cell loss. HIV infection triggers a general activation of the immune system that persists for years, which may eventually result in exhaustion of the regenerative capacities of the immune system,

\footnotetext{
* Correspondence: scheller@vim.uni-wuerzburg.de

'University of Wuerzburg, Institute of Virology und Immunobiology, 97078 Wuerzburg, Germany

Full list of author information is available at the end of the article
}

causing immunodeficiency and AIDS [1-3]. The trigger for this chronic stimulation is probably multifactorial, including a direct stimulation of HIV-specific cells by the ongoing replication of HIV [4]. Furthermore, elevated levels of plasma lipopolysaccharide (LPS) and bacterial DNA in chronic HIV patients suggest that microbial translocation from the damaged gut contributes to this hyperactivation by triggering an innate immune response to Gram-negative bacteria [5,6]. During this process, the two host factors LPS binding protein (LBP) and soluble CD14 neutralize plasma LPS and
C Biomed Central

(C) 2011 Kasang et al; licensee BioMed Central Ltd. This is an Open Access article distributed under the terms of the Creative Commons Attribution License (http://creativecommons.org/licenses/by/2.0), which permits unrestricted use, distribution, and reproduction in any medium, provided the original work is properly cited. 
direct it to the Toll-like receptor (TLR)-4 molecule expressed on macrophages $[7,8]$.

The pivotal role of chronic immune activation in HIV pathogenesis is underlined by the fact that immune activation parameters such as expression of CD38 or HLA-DR on CD8+ $\mathrm{T}$ are good predictors of subsequent $\mathrm{T}$ cell loss and correlate much better with HIV disease progression than plasma viral load or chemokine coreceptor usage [2]. In a similar way, plasma levels of soluble sCD14, LBP and soluble urokinase plasminogen activator receptor (suPAR) correlate with HIV disease progression $[2,9,10]$. The transmembrane glycoprotein CD40L (CD154), a member of the tumor necrosis factor family, is primarily expressed on activated CD4+ T cells, but also detected on many other cell populations including a small proportion of CD8+ cells [11]. The soluble form (sCD40L) still binds to the receptor and delivers biological signals in a cytokine-like manner [12]. Increased sCD40L levels were detected in the serum of HIV-infected patients [13].

Chronic immune activation as a consequence of immunodeficiency virus infection is restricted to man and Asian monkeys, who both develop AIDS following untreated HIV/SIV infection. In contrast, African monkeys which do not exhibit chronic immune activation following SIV infection do not progress to AIDS and remain healthy, despite high viral load $[6,14,15]$.

Treatment with antiretroviral therapy does not only suppress virus replication but also substantially reduces HIVassociated general immune activation [16-21]. Compared to uninfected controls, HAART-treated patients however still exhibit slightly elevated immune activation that is being considered a risk factor for ongoing disease progression (albeit at much slower pace than in untreated patients) [22-27]. Despite the dramatic success of antiretroviral therapy on reduction of mortality in HIV infection, HIV-infected patients treated with HAART still have a life expectancy below the average of the uninfected population [28]. Immune-based therapies that aim to further reduce immune activation under HAART may therefore further close this gap. In resource-limited areas with later onset of HAART compared to more industrialized countries, cheap and robust immunomodulating regimens preceding antiretroviral therapy may be another option to reduce worldwide HIV mortality until HAART becomes universally available.

In this study we investigated general immune activation in HIV patients who received low-dose (5 mg/day) prednisolone in combination with or without HAART compared to untreated patients.

\section{Methods}

\section{Subjects}

The patients analyzed in this study received HIV-treatment according to the treatment recommendations of the "Deutsche AIDS Gesellschaft" (DAIG). In addition to antiretroviral medication, some of our patients also received low-dose (5 $\mathrm{mg} /$ day) prednisolone as part of their individual treatment plan. Among the $101 \mathrm{HIV}$ patients included into our study, 27 received low-dose ( $5 \mathrm{mg} /$ day) prednisolone, 31 received low-dose prednisolone in combination with HAART, 30 received HAART alone and 13 received neither HAART nor prednisolone.

\section{Prednisolone medication}

We (A. Ulmer) have previously reported that HIV patients who do not yet meet the eligibility criteria for antiretroviral therapy seem to profit from treatment with low-dose ( $5 \mathrm{mg}$ per day) prednisolone by a stabilization of helper $\mathrm{T}$ cell counts compared to patients that remained therapy-naive $[29,30]$. Due to these encouraging observations, patients at the site of A. Ulmer are being offered low-dose prednisolone (prior or accompanying to HAART) and patients decide individually of whether or not to receive prednisolone. We therefore supervise a population of patients that can be categorized into four subgroups: untreated-patients, prednisolone-treated patients, and at later stages of the infection HAART-treated patients who receive or do not receive prednisolone. All patients investigated in this study derive from the same study center (A. Ulmer), which was the only participating site that could enroll prednisolone-treated patients. To compare immune activation in patients with therapeutic (HAART) and immunologic control of virus replication, we included 3 additional treatment-naïve patients (elite controllers who suppress virus replication beyond the detection limit of 50 copies $/ \mathrm{ml}$ ) from another site (H. Klinker).

\section{Study design}

In an observational study we compared immune activation parameters in 5 different subject groups: (1) HIV-1infected subjects who receive neither HAART nor prednisolone and with detectable viral load, referred to as "untreated"; (2) HIV-1 infected subjects treated with 5 $\mathrm{mg} /$ day prednisolone, referred to as "Prednisolone"; (3) HIV-1 infected subjects treated with antiretroviral therapy, referred to as "HAART"; (4) HIV-infected subjects treated with antiretroviral therapy in combination with $5 \mathrm{mg} /$ day prednisolone, referred to as "HAART+Prednisolone"; (5) HIV-1 infected subjects as described for (1) but with undetectable viral load referred to as "elite controllers". Patients have been asked to participate in the study during their routine visits at the site. Patients willing to participate in the study signed an informed consent. No additional selection criteria other than willingness to participate were applied for inclusion into the study. 
The study was approved by the ethical committees of the Landesärztekammer Baden-Württemberg, the Bayerische Landesärztekammer, and the University of Würzburg.

\section{Isolation of plasma}

$7.5 \mathrm{ml}$ of whole blood were collected from each patient with a vacutainer supplemented with EDTA (BD Biosciences) for flow cytometric analysis of PBMC. EDTA plasma was used for SCD40L-ELISA. Additional $8 \mathrm{ml}$ of blood were collected for plasma preparation from heparin-blood. Heparin-plasma was used for sCD14and LBP-ELISAs.

\section{Flow cytometry}

Fresh EDTA-blood was used within $8 \mathrm{~h}$ after collection. Erythrocytes were lysed using a lysis solution (BD Biosciences) and PBMC were stained in triplicates with antibodies directed at CD3 (labeled with FITC) and CD8+ (labeled with PerCP) and counterstained with antiCD38-PE (all antibodies from were purchased from BD Biosciences, Heidelberg, Germany) according to the "lysis no wash" protocol (BD Biosciences). Cells were analyzed by flow cytometry using a FACS-Calibur flow cytometer (Becton Dickinson). Markers were set according to cells stained with fluorochrome-conjugated isotype control antibodies (all from BD Biosciences).

Lymphocytes were identified by gating in a dot plot of forward and sideward scatter (FSC/SSC). For analysis of $\mathrm{T}$ cell activation, cells were stained with anti-CD3 (PerCP)/CD8(FITC)/CD38(PE)-antibodies. CD3+/CD8+ cells within the FSC/SSC lymphocyte gate were scored as CD8+ T-lymphocytes. CD3+/CD8- cells within the FSC/SSC lymphocyte gate were scored as CD4-positive $\mathrm{T}$ cells. CD38 expression was determined in CD3+/CD8 + lymphocytes (CD8 T lymphocytes) and CD3+/CD8lymphocytes (scored as CD4+ T lymphocytes). CD38+ lymphocytes were scored as activated cells. For analysis of naïve $\mathrm{T}$ cells, cells were stained with anti-CD3 (PerCP)/CD4(APC)/CD45RA(FITC)/CD62L(PE)-antibodies. $\mathrm{CD} 3+/ \mathrm{CD} 4+$ cells within the FSC/SSC lymphocyte gate were scored as CD4+ T-lymphocytes. CD3+/CD4cells within the FSC/SSC lymphocyte gate were scored as CD8-positive T cells. CD45RA/CD62L-expression was determined in CD3+/CD4+ lymphocytes (CD4 T lymphocytes) and CD3+/CD4- lymphocytes (scored as CD8+ T cells). CD45RA/CD62L-positive lymphocytes were scored as naïve cells.

\section{Viral load and CD4 counts}

CD4 counts and viral load were determined from EDTA-blood by a commercial virusdiagnostic laboratory during routine medical care (CD4: Prof. Enders, Stuttgart, viral load: Dr. Jaegel-Guedes/Jäger, München).

\section{sCD14, LBP, suPAR and sCD40L}

ELISAs to detect plasma levels of sCD14 (Diaclone), LBP (Hycult Biotech), suPAR (ViroGates) and sCD40L (Bender MedSystems) were performed according to the manufacturer's instructions. For the latter, $100 \mu \mathrm{l}$ of EDTA plasma samples were analyzed that had been thawed once.

\section{Statistical analysis}

Statistical analysis was performed using the GraphPad Prism software (version 4.0c for Macintosh). About half of the data showed a non-Gaussian distribution (according to D'Agostino-Pearson test) so that medians and interquartile range (expressed as $25 \%-75 \%$ percentile) were chosen to describe the results. Differences between untreated and Prednisolone-treated or HAART-treated and HAART + Prednisolone-treated groups were analyzed by Mann-Whitney $U$-test and $p<0.05$ was regarded as statistically significant. Correlations were performed using linear regression.

\section{Results}

\section{Patient population}

In this observational study we analyzed general immune activation parameters in patients with HIV infection receiving individual therapy regimes. Patients who were willing to participate in the study gave written informed consent and donated a single blood sample. We divided the patients into five different groups, including a) untreated patients $(\mathrm{n}=10), \mathrm{b})$ patients being treated with low-dose prednisolone $(\mathrm{n}=27), \mathrm{c})$ with HAART (n = 30), d) HAART plus prednisolone $(\mathrm{N}=31)$ or e) treatment-naïve patients with undetectable viral load (Table 1). At the time of blood sampling, the 27 patients in the prednisolone group received prednisolone medication for a median duration of 2.3 years (Table 1 ). Although the exact time of infection for each patient is unknown, the date of the first HIV diagnosis indicates that patients in the prednisolone and HAART groups are probably much longer infected with HIV (median of 9 years in both HAART groups and median of 5 years in the prednisolone-only group) than patients in the notreatment group (median of 2 years) (Table 1 ).

Values represent medians [interquartile range as $25 \%$ $75 \%$ percentile]. *) As the number of elite controllers in this study is only 3, all three single values are depicted instead of the median. Cutoff for viral load (VL) for all patients is 40 copies/ml plasma, except for the three patients (elite controllers) derived from $\mathrm{H}$. Klinker with a detection limit of 50 copies/ml. Values in double brackets $[[\mathrm{x}]]$ represent VL of individual HAART-treated patients with detectable VL. ${ }^{* *}$ ) For 7 patients treated with HAART+prednisolone the exact time of prednisolone treatment was unknown but their medical records 
Table 1 Patient characteristics

\begin{tabular}{|c|c|c|c|c|c|}
\hline Treatment group & $\begin{array}{l}\text { Untreated }(\mathrm{n}= \\
10)\end{array}$ & $\begin{array}{l}\text { Prednisolone (n } \\
\quad=27 \text { ) }\end{array}$ & HAART & Prednisolone/HAART & $\begin{array}{l}\text { no treatment, elite } \\
\text { controllers }\end{array}$ \\
\hline number of patients & 10 & 27 & 30 & 31 & 3 \\
\hline age in years & 39 [28.0-50.5] & 38 [32.0-47.0] & $47[42.5-61.0]$ & 48 [40.0-58.0] & $28,43,56^{*}$ \\
\hline $\mathrm{sex} \mathrm{m} / \mathrm{f}$ & $9 \mathrm{~m} / 1 \mathrm{f}$ & $22 \mathrm{~m} / 5 \mathrm{f}$ & $24 \mathrm{~m} / 6 \mathrm{f}$ & $23 \mathrm{~m} / 8 \mathrm{f}$ & $2 \mathrm{~m} / 1 \mathrm{f}$ \\
\hline $\begin{array}{l}\text { time since first HIV } \\
\text { diagnosis in years }\end{array}$ & $2[1.0-4.0]$ & $5[3.0-13.0]$ & 9 [4.5-16.0] & $9[3.0-14.0]$ & $3,15,21^{*}$ \\
\hline $\begin{array}{l}\text { prednisolone treatment } \\
\text { in years }\end{array}$ & n.a. & $2.3[1.2-3.5]$ & n.a. & $5[2.0-5.7]^{* *}$ & n.a. \\
\hline $\begin{array}{l}\text { viral load (RNA copies/ml } \\
\text { plasma) }\end{array}$ & $\begin{array}{c}1.1 \times 10^{5}[0.5- \\
\left.12.2 \times 10^{5}\right]\end{array}$ & $\begin{array}{l}0.8 \times 10^{5}[0.2- \\
\left.42.4 \times 10^{5}\right]\end{array}$ & $\begin{array}{c}27 \text { undetectable, others } \\
{[[46 ; 66 ; 191]]}\end{array}$ & $\begin{array}{l}25 \text { undetectable, others: }[[41 ; 46 ; \\
63 ; 74 ; 131 ; 1085]]\end{array}$ & undetectable \\
\hline CD4+ counts (cells/ul) & 520 [350-670] & 550 [460-700] & $465[320-655]$ & $390[280-600]$ & $284,554,892^{*}$ \\
\hline
\end{tabular}

documented treatment for more than 5 years. For the calculation of the median, the time of treatment for these patients was set to 5 years

\section{Viral load}

Patients in the no-treatment and prednisolone-treatment groups presented with comparable amounts of viral load (medians $1.1 \times 10^{5}$ and $0.8 \times 10^{5}$, respectively) (Table 1). Most of the patients who received HAART (both in combination with or absence of prednisolone) had undetectable viral load (below 40-50 copies/ml).

\section{CD38-expression on $\mathrm{T}$ cells}

$\mathrm{T}$ cell activation was studied by flow cytometric analysis of whole blood stained with anti-CD3/CD8/CD38. CD3positive/CD8-negative cells were scored as CD4-positive $\mathrm{T}$ lymphocytes. Patients in the prednisolone group exhibited statistically significant lower activation of CD8 $+\mathrm{T}$ cells than patients in the untreated group patients (median 55.40\% [percentile range 48.76-67.70] versus $73.34 \%$ [65.21-78.92], $p=0.0011$ ). (Figure 1A). The lowest activation rates were measured in HAART and HAART+prednisolone-treated patients (median 22.07\% [15.49-38.27] versus $28.85 \%$ [20.69-36.87]) and prednisolone comedication had no detectable effect on CD8-activation in HAART-treated patients $(p=0.2515)$. CD38expression on CD8 T cells in patients receiving HAART was similar to CD38 expression in "elite controllers" but due to the very limited number of patients in this group $(\mathrm{n}=3)$ we will not go into further details.

Prednisolone medication had apparently no effect on CD38 expression in CD8-negative T cells, independent of whether patients received prednisolone in the absence or presence of HAART (Figure 1B)

\section{sCD14 and LBP}

In order to determine the effects of low-dose prednisolone on monocyte activation associated with the LPSresponse, we analyzed levels of soluble CD14 (sCD14) and LPS-binding protein (LBP). We found significantly lower concentrations of plasma $\mathrm{SCD} 14$ in patients treated with prednisolone alone compared to untreated patients $(3.6 \mu \mathrm{g} / \mathrm{ml}[2.78-5.12]$ vs. $6.11 \mu \mathrm{g} / \mathrm{ml}[4.58$ 7.70]; $p=0.0048$ ) (Figure 2A). No effects attributable to prednisolone could be observed in HAART-treated patients. Similar to what we found for SCD14 levels, patients in the prednisolone-only group showed significantly lower LBP-levels compared to untreated patie2Ants $(2.18 \mathrm{ng} / \mathrm{ml}[1.59-2.87]$ vs. $3.45 \mathrm{ng} / \mathrm{ml}$ [1.845.03]; $p=0.0386$ ) (Figure 2B), and again no additional effects related to prednisolone were observed in HAART-treated patients.

\section{sUPAR and SCD40L}

Comparing patients treated with prednisolone alone and untreated patients, significantly lower concentrations of plasma suPAR levels were detected in prednisolone-treated patients $(2.17 \mu \mathrm{g} / \mathrm{ml}[1.65-2.81]$ vs. $2.56 \mu \mathrm{g} / \mathrm{ml}[2.24-$ 4.26]; $p=0.0351$ ) as well as a strong trend towards lower levels of sCD40L $(2.70 \mathrm{pg} / \mathrm{ml}$ [1.90-4.00] vs. 3.60 $\mathrm{pg} / \mathrm{ml}[2.95-5.30] ; p=0.0782$ ) (Figure 3B). In the presence of HAART, no effects attributable to prednisolone could be observed for the two markers (Figure 3A, B).

\section{CD4 T cell counts, CD4/CD8 ratio and naïve cells}

As depicted in Figure 4A, patients treated with prednisolone-only presented with $\mathrm{CD} 4+\mathrm{T}$ cell counts comparable to untreated patients (550 cells $/ \mu \mathrm{l}$ [460-700] vs. 520 cells $/ \mu \mathrm{l}$ [350-670]; $p=0.7067)$. Patients treated with HAART or HAART/prednisolone exhibited a trend towards lower CD4 T cell counts compared to therapy naïve and prednisolone-treated patients. The CD4/CD8 ratio in prednisolone-only-treated patients was significantly decreased compared to treatment-naïve patients (ratio 0.46 [0.38-0.72] vs. ratio 0.755 [0.55-0.97]), and comparable to HAART and HAART/prednisolone-treated patients (Figure 4B). As the CD4+ T cell counts in prednisolone-treated and naive patients are similar 


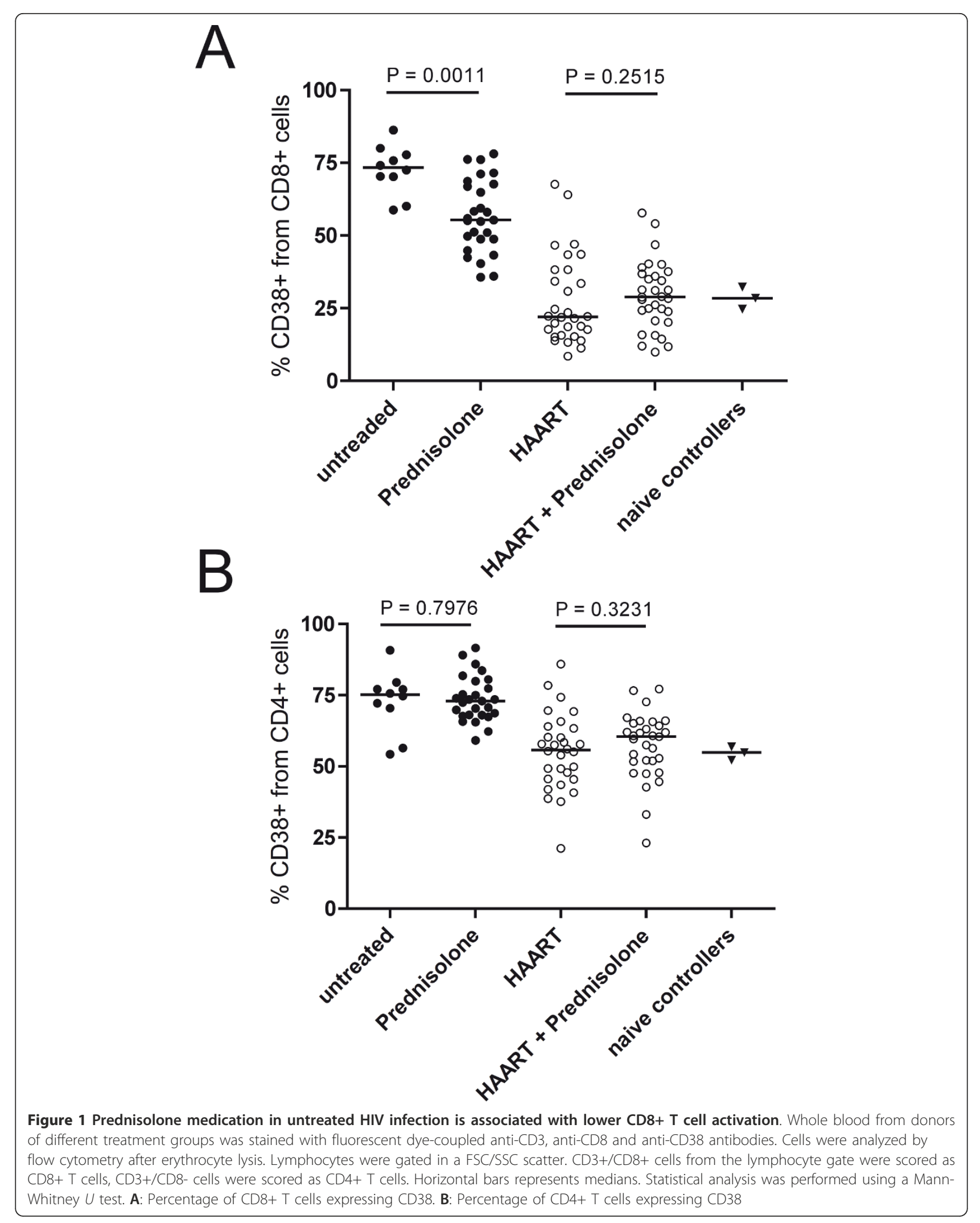




\section{A}

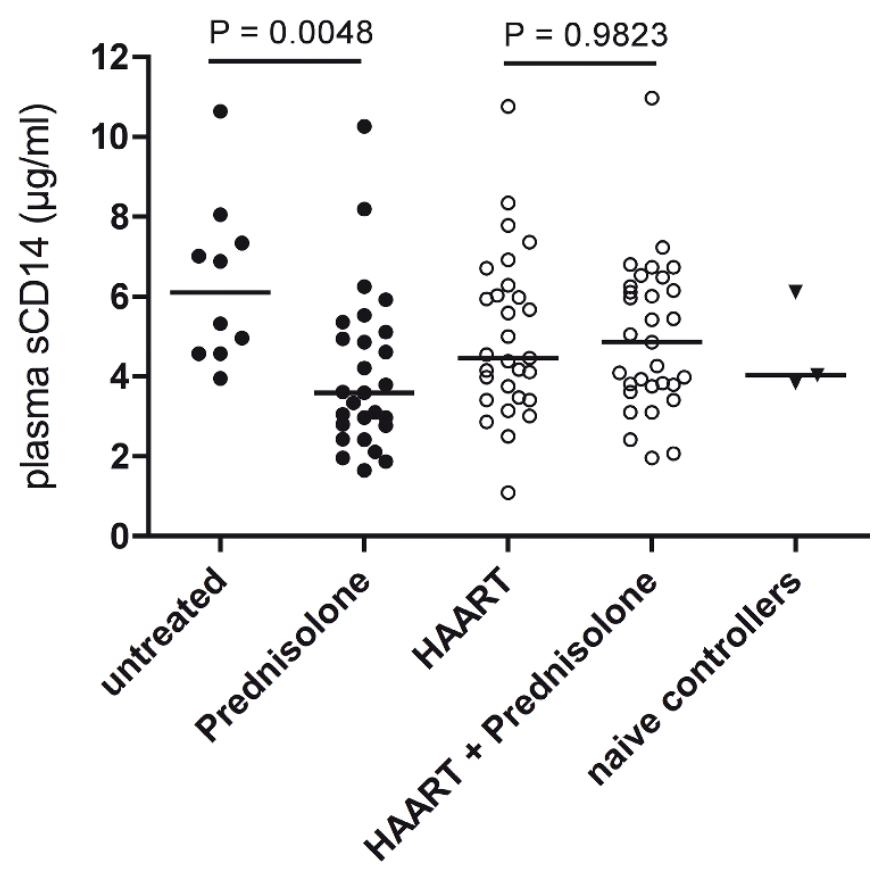

B

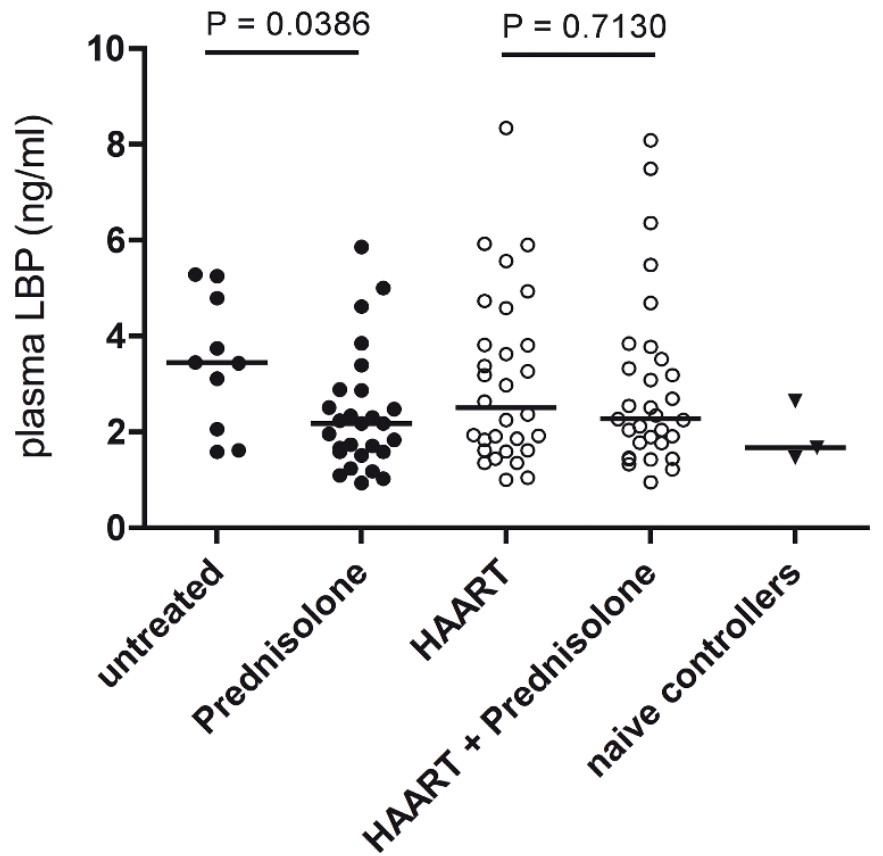

Figure 2 Prednisolone medication in untreated HIV infection is associated with lower monocyte activation. SCD14 and LBP concentrations were determined by ELISA from plasma from donors of different treatment groups. Horizontal bars represents medians. Statistical analysis was performed using a Mann-Whitney $U$ test. A: Plasma concentrations of sCD14. B: Plasma concentrations of LBP. 


\section{A}
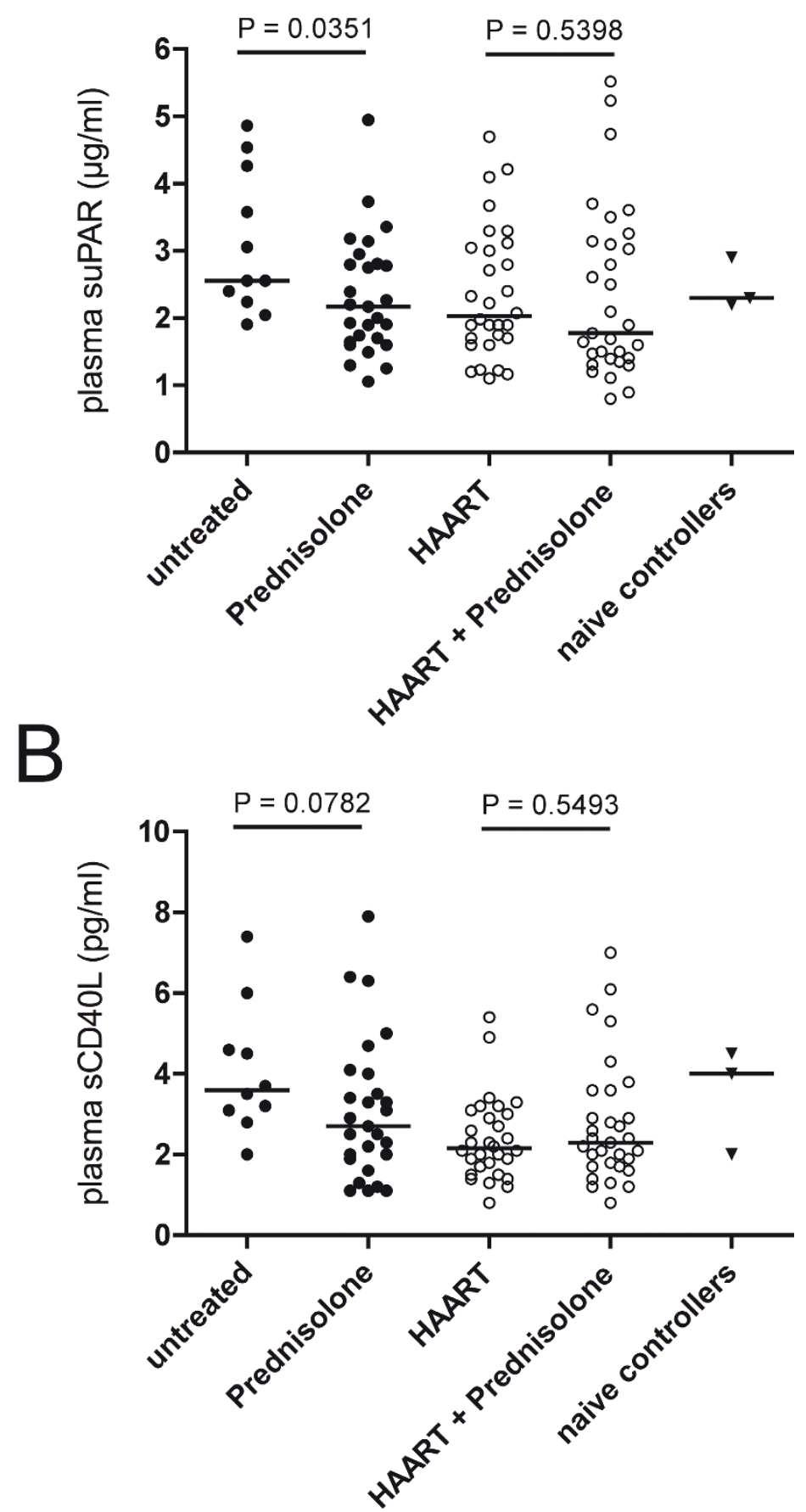

Figure 3 Prednisolone medication in untreated HIV infection is associated with lower inflammation. Concentrations of suPAR and SCD40L were determined by ELISA from plasma from donors of different treatment groups. Horizontal bars represents medians. Statistical analysis was performed using a Mann-Whitney test U-test. A: sUPAR. B: SCD40L. 


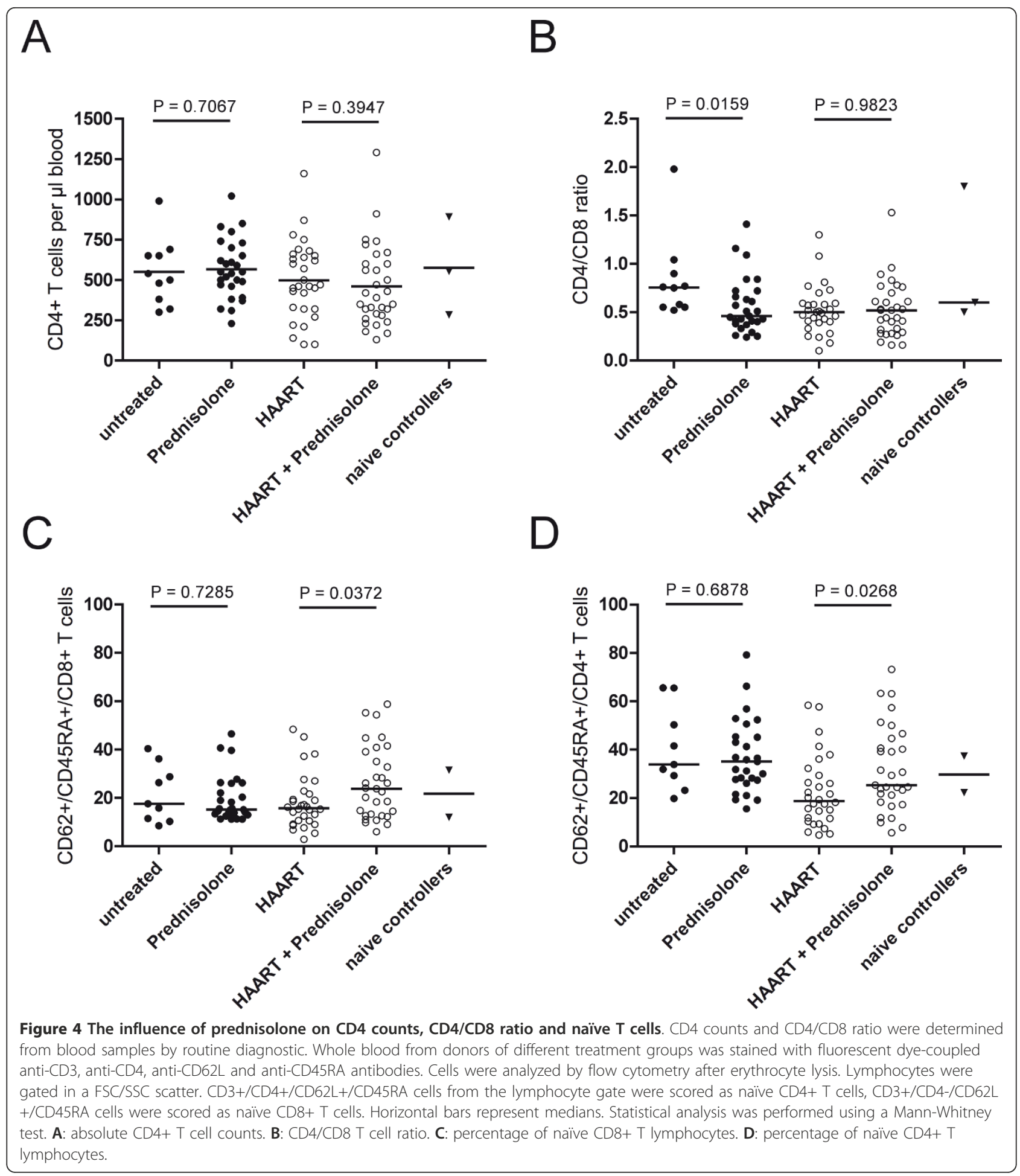

(Figure $4 \mathrm{~A}$ ), the decrease of the observed CD4/CD8 ratio in prednisolone-treated patients reflects a relative increase of the CD8+ T cell population. This increase could be a direct consequence of the observed reduced immune activation of this population (Figure 1A), which may translate into reduced turnover rates.
In patients treated with HAART, prednisolone-medication was associated with a significantly higher percentage of memory (CD62L+/CD45RA + ) CD $8+\mathrm{T}$ cells (23.8\% [12.6 - 39.1] vs. $15.8 \%$ [9.84-22.25]; $p=0.0372)$ (Figure 4C) and memory CD4+ T cells $(25.4 \%$ [18.3 $44.6]$ vs. $18.8 \%[10.9-30.85] ; p=0.0268$ ) (Figure $4 \mathrm{D}$ ). No 
effects attributable to prednisolone on the frequency of naive $\mathrm{T}$ cells were detected between untreated and prednisolone-only-treated patients.

\section{Discussion}

In this study we investigated factors of general immune activation associated with HIV disease progression, and we found significantly lower values in patients receiving prednisolone compared to untreated patients, suggesting that prednisolone may have beneficial effects on immunological correlates of HIV disease progression in otherwise untreated patients. In patients treated with HAART, no additional beneficial effects attributable to prednisolone could be observed. The immune-modulating activity of prednisolone in otherwise untreated patients described in this manuscript is in line with previous observations, reported by Andrieu et al., who observed in an uncontrolled, open-label study an increase in CD4 $+\mathrm{T}$ cell counts following administration of $0.3-0.5 \mathrm{mg} / \mathrm{kg}$ prednisolone over a period of 12 months [31]. Prednisolone treatment (with a concentration about 4-8 times higher than in our study) was accompanied by a reduction of immune activation. Patients were encouraged to continue $0.3 \mathrm{mg} / \mathrm{kg}$ prednisolone as follow up-medication as long as their CD4+ T cell levels remained above baseline levels. Follow-up prednisolone treatment postponed CD4+ T cell decrease (relative to baseline levels) by two years [32]. A few patients experienced relatively mild prednisolone-associated side effects such as face swelling, an increase in body weight and elevated blood pressure.

In another, randomized, placebo-controlled trial, prednisolone was given for 8 weeks with a decreasing dose from $50 \mathrm{mg}$ to $15 \mathrm{mg}$ per day; the main outcome was survival [33]. Elliot and colleagues observed only a trend towards better survival in prednisolone-treated patients compared to HIV controls (21 versus 25 deaths per 100 person years; difference statistically not significant) but a statistically significant increase in the incidence of Kaposi sarcoma (4.2 versus 0 cases per 100 person years). The study population was not being stratified for HHV-8 seropositivity, the causative factor of Kaposi sarcoma, and HHV-8 infection status was not being analyzed. (In another short-term randomized, placebocontrolled trial studying the effects of prednisolone on effusive tuberculous pericaditis in HIV-infected individuals, with a similar dosage and time scale $[60 \mathrm{mg}$ starting dose, tapered with $10 \mathrm{mg}$ per week until completion at the sixths week], three cases of Kaposi sarcoma were observed among the 58 study participants and all of them received placebo [34].) The main difference in the treatment regime towards other studies, including ours, is the relative short duration of prednisolone treatment of only 8 weeks, which may hamper the observation of a therapeutic benefit with the primary endpoint of survival.

Two other randomized, placebo-controlled trials investigated the effects of prednisolone on HIV-infection in the presence of HAART. In a study with a dose of 0.5 mg per kg body weight per day given for 8 weeks, a decrease in CD8+/CD38+ cells was reported with no changes in viral load and CD4+ cell counts [35]. In partial contrast to this, a fixed daily dose of $40 \mathrm{mg}$ prednisolone was given for 8 weeks in another trial, resulting in an increase of CD4+ counts compared to baseline values of $40 \%$, but no changes in HLADR/CD38-positive CD8 cells and naive $T$ cells (CD45RA+/CD62L+) were reported [36].

We have previously analyzed the CD4+ cell counts of some of our patients in a longitudinal observational study and found that long-term treatment with low-dose prednisolone is safe and - similar to what has been found by Andrieu et al. [31] - associated with a postponement of CD4+ T cell loss by about 2 years relative to baseline values $[29,30]$. Our present study may offer a mechanistic explanation for the $\mathrm{T}$ cell preserving activity of low-dose prednisolone, i.e. by reducing general immune activation. Unfortunately, the previously described CD4+ T cell preserving activity of prednisolone cannot be directly addressed in this study (although a trend towards higher counts in prednisolone-treated patients was visible), as this would require a longitudinal analysis and probably also a more homogenous patient sample with respect to time to infection and therapy initiation.

The strong association between general immune activation and HIV disease progression is also seen in studies investigating the effects of HAART on immune activation. Similar to what we found in our study, HAART does not only suppress virus replication but also reduces immune activation [18-20]. In some patients - the so-called virological nonresponders HAART fails to suppress virus replication but effectively restores immune activation and CD4 T cell counts [37]. On the other hand, immunological nonresponders, who do not regenerate helper $\mathrm{T}$ cell counts despite HAARTmediated suppression of virus replication, show enhanced immune activation [38]. Massanella et al. reported in a cross sectional study that patients with limited CD4 T-cell repopulation under HAART exhibited high $\mathrm{T}$-cell activation rates (CD38+, HLA-DR+), suggesting that immunomodulating strategies should be envisaged to treat discordant patients [39].

General immune activation not only correlates with progression of immunodeficiency, but also with neurological complications of HIV infection. HIV patients with cognitive impairment or brain atrophy exhibit more elevated sCD14 levels than neurologically asymptomatic 
HIV-positive controls [40]. This link between monocyte activation and the neurological complications of HIV infection fits well into the overall picture in which microglia activation has been identified as a correlate with immunodeficiency virus-mediated neuropathy $[41,42]$.

Due to the non-prospective and non-randomized design of our study, our findings should be interpreted with caution, as potential yet undiscovered confounding mechanisms may have biased the result. Moreover, the low sample size of our study is relatively low and differences in individual viral loads (although not statistically significant between untreated and prednisolone-treated patients) are possible limitations. As we found significantly lower immune activation in patients treated with prednisolone compared to untreated patients, the critical reader might object that this difference might have been caused by an unintended enrichment of natural slowprogressors in the group of prednisolone-treated patients over time, who would lower the average immune activation in this group due to intrinsically lower immune activation in these patients. (The argument in this case would be that patients who progressed under prednisolone sooner or later would have left this group to become treated with HAART. Hence, over time, patients with an intrinsic slower disease progression would have become enriched in this group. At a closer look, this mechanism would, however, also apply for patients in the untreated group - compared to which prednisolone-treated patients exhibited significantly lower activation.) We therefore checked whether there is any correlation in prednisolone-treated patients between immune activation (CD8/CD38, sCD14, LBP, suPAR) and the duration of prednisolone medication or the (known) time of infection and found no correlation whatsoever for any of the markers (P values of correlations ranged between 0.2748 and 0.9399 , data not shown). These findings suggest that a prednisoloneindependent enrichment over time of slow-progressing patients in this group has not taken place, otherwise one should have expected to observe lower levels of immune activation in patients with longer treatment times.

As for the absence of detectable effects of prednisolone in HAART-treated patients in almost all analyzed parameters in this study, this may well be attributed to the heterogeneity of the patients (differences in CD4 counts, time to infection), differences in the composition of individual antiretroviral regimens that may have different effects on immune activation or to the low dose of prednisolone used. Further studies specifically addressing the effects of prednisolone in the presence of HAART looking at more homogenous patient groups are therefore needed. Studying the effects of immune modulators in the presence of HAART (in contrast to immune modulators preceding HAART) is of particular interest, since there is residual immune activation in HAART-treated patients associated with accelerated disease progression [25].

In countries with lesser access to (and therefore later onset of) HAART, prednisolone medication preceding antiretroviral treatment might be considered as a supplement regimen in HIV therapy, provided that prednisolone-mediated immune modulation is safe and translates into a clinical benefit for the patients. In order to address this question, we are currently performing a randomized, double-blinded, placebo-controlled clinical trial to assess the effects of low-dose prednisolone on immune activation and HIV disease progression in otherwise treatment-naïve patients, recruiting 326 patients in Tanzania (trial name: "ProCort1"; registry: http://ClinicalTrials.gov; registration number: NCT01299948). Recruitment is now completed and first results will be available soon.

\section{Conclusions}

General immune activation is considered to be a key factor for HIV disease progression and the results of our study indicate that treatment with low-dose prednisolone may reduce this activation. Further studies are required to analyze whether attenuation of immune activation achieved by immunomodulatory substances translates into clinical benefit for the patients.

\section{List of abbreviations}

AIDS: acquired immunodeficiency syndrome; EDTA: ethylene-diamin tetraacetic acid; ELISA: enzyme-linked immunosorbent assay; FCS/SSC: forward scatter/sideward scatter; HAART: highly-active antiretroviral therapy; HHV-8: human herpesvirus 8; HIV: human immunodeficiency virus; LBP: LPSbinding protein; LPS: lipopolysaccharide; PBMC: peripheral blood mononuclear cells; SIV: simian immunodeficiency virus; sUPAR: soluble urokinase plasminogen activator receptor

\section{Acknowledgements}

We thank Ingeborg Euler-König, Waltraud Tuchel and Cornelia Meinhold for excellent technical assistance. The study was supported by grants from the "Deutsche Forschungsgemeinschaft" (GRK 1522/1, SCHM1703/3-1), the ELAN fonds (VI-08-06.18.1) and the "Gesellschaft für AIDS-Forschung". C.K. was supported by the "Evangelisches Studienwerk e.V. Villigst". A. Ulmer and B. Schmidt are members of the German competence network HIV/AIDS. Publication costs were covered by the Deutsche Forschungsgemeinschaft http://www.dfg.de and the University of Würzburg http://www.uniwuerzburg.de by the funding programme "Open Access Publishing." The funders had no role in study design, data collection and analysis, decision to publish, or preparation of the manuscript.

\section{Author details}

${ }^{1}$ University of Wuerzburg, Institute of Virology und Immunobiology, 97078 Wuerzburg, Germany. ${ }^{2}$ HIV-Intensive Care Unit, Schwabstr. 26, 70197 Stuttgart, Germany. ${ }^{3}$ Institute of Virology, Clinical and Molecular Virology, National Reference Center for Retroviruses, University of Erlangen-Nuernberg, Erlangen, Germany. ${ }^{4}$ Medical Mission Institute, Department of Tropical Medicine, 97067 Wuerzburg, Germany. ${ }^{5}$ University of Wuerzburg, Medical Clinic and Policlinic II, Josef-Schneider-Str. 2, 97080 Wuerzburg, Germany. ${ }^{6}$ Bugando Medical Center, Mwanza, Tanzania. 


\section{Authors' contributions}

CK, AU, AS, SK and CS participated in the design and coordination of the study. CK, ND, BS, and CS carried out the immune activation studies. BS and CS performed the statistical analysis. CK, AU, BS, AS, HK, EK, AR and CS drafted the manuscript and CS wrote its final version. All authors read and approved the final manuscript.

\section{Competing interests}

The authors declare that they have no competing interests.

Received: 1 August 2011 Accepted: 20 January 2012

Published: 20 January 2012

\section{References}

1. Deeks SG, Kitchen CM, Liu L, Guo H, Gascon R, Narvaez AB, Hunt P, Martin JN, Kahn JO, Levy J, et al: Immune activation set point during early HIV infection predicts subsequent CD4+ T-cell changes independent of viral load. Blood 2004, 104(4):942-947.

2. Giorgi JV, Hultin LE, McKeating JA, Johnson TD, Owens B, Jacobson LP, Shih R, Lewis J, Wiley DJ, Phair JP, et al: Shorter survival in advanced human immunodeficiency virus type 1 infection is more closely associated with $\mathrm{T}$ lymphocyte activation than with plasma virus burden or virus chemokine coreceptor usage. J Infect Dis 1999, 179(4):859-870

3. Hazenberg MD, Otto SA, van Benthem BH, Roos MT, Coutinho RA, Lange JM, Hamann D, Prins M, Miedema F: Persistent immune activation in HIV-1 infection is associated with progression to AIDS. AIDS 2003, 17(13):1881-1888.

4. Fauci AS: Multifactorial nature of human immunodeficiency virus disease: implications for therapy. Science 1993, 262(5136):1011-1018.

5. Jiang W, Lederman MM, Hunt P, Sieg SF, Haley K, Rodriguez B, Landay A, Martin J, Sinclair E, Asher Al, et al: Plasma Levels of Bacterial DNA Correlate with Immune Activation and the Magnitude of Immune Restoration in Persons with Antiretroviral-Treated HIV Infection. J Infect Dis 2009, 199(8):1177-1185

6. Brenchley JM, Price DA, Schacker TW, Asher TE, Silvestri G, Rao S, Kazzaz Z, Bornstein E, Lambotte O, Altmann D, et al: Microbial translocation is a cause of systemic immune activation in chronic HIV infection. Nat Med 2006, 12(12):1365-1371.

7. Kitchens RL, Thompson PA: Modulatory effects of sCD14 and LBP on LPShost cell interactions. J Endotoxin Res 2005, 11(4):225-229.

8. Cohen J: The immunopathogenesis of sepsis. Nature 2002, 420(6917):885-891

9. Lien E, Aukrust P, Sundan A, Muller F, Froland SS, Espevik T: Elevated levels of serum-soluble CD14 in human immunodeficiency virus type 1 (HIV-1) infection: correlation to disease progression and clinical events. Blood 1998, 92(6):2084-2092.

10. Ostrowski SR, Piironen T, Hoyer-Hansen G, Gerstoft J, Pedersen BK, Ullum H: High plasma levels of intact and cleaved soluble urokinase receptor reflect immune activation and are independent predictors of mortality in HIV-1-infected patients. J Acquir Immune Defic Syndr 2005, 39(1):23-31.

11. van Kooten C, Banchereau J: CD40-CD40 ligand. J Leukoc Biol 2000, 67(1):2-17

12. Mazzei GJ, Edgerton MD, Losberger C, Lecoanet-Henchoz S, Graber P, Durandy A, Gauchat JF, Bernard A, Allet B, Bonnefoy JY: Recombinant soluble trimeric CD40 ligand is biologically active. J Biol Chem 1995, 270(13):7025-7028.

13. Sipsas NV, Sfikakis PP, Kontos A, Kordossis T: Levels of soluble CD40 ligand (CD154) in serum are increased in human immunodeficiency virus type 1-infected patients and correlate with CD4(+) T-cell counts. Clin Diagn Lab Immunol 2002, 9(3):558-561.

14. Pandrea I, Onanga R, Kornfeld C, Rouquet P, Bourry O, Clifford S, Telfer PT, Abernethy $K$, White LT, Ngari P, et al: High levels of SIVmnd-1 replication in chronically infected Mandrillus sphinx. Virology 2003, 317(1):119-127.

15. Silvestri G, Sodora DL, Koup RA, Paiardini M, O'Neil SP, McClure HM, Staprans SI, Feinberg MB: Nonpathogenic SIV infection of sooty mangabeys is characterized by limited bystander immunopathology despite chronic high-level viremia. Immunity 2003, 18(3):441-452.

16. Autran B, Carcelain G, Li TS, Blanc C, Mathez D, Tubiana R, Katlama C, Debre $P$, Leibowitch J: Positive effects of combined antiretroviral therapy on CD4+ T cell homeostasis and function in advanced HIV disease. Science 1997, 277(5322):112-116.
17. Lederman MM, Connick E, Landay A, Kuritzkes DR, Spritzler J, St Clair M, Kotzin BL, Fox L, Chiozzi MH, Leonard JM, et al: Immunologic responses associated with 12 weeks of combination antiretroviral therapy consisting of zidovudine, lamivudine, and ritonavir: results of AIDS Clinical Trials Group Protocol 315. J Infect Dis 1998, 178(1):70-79.

18. Bisset LR, Cone RW, Huber W, Battegay M, Vernazza PL, Weber R, Grob PJ, Opravil M: Highly active antiretroviral therapy during early HIV infection reverses T-cell activation and maturation abnormalities. Swiss HIV Cohort Study. AIDS 1998, 12(16):2115-2123.

19. Dyrhol-Riise AM, Voltersvik P, Olofsson J, Asjo B: Activation of CD8 T cells normalizes and correlates with the level of infectious provirus in tonsils during highly active antiretroviral therapy in early HIV-1 infection. AIDS 1999, 13(17):2365-2376.

20. Gray CM, Schapiro JM, Winters MA, Merigan TC: Changes in CD4+ and CD8 $+T$ cell subsets in response to highly active antiretroviral therapy in HIV type 1-infected patients with prior protease inhibitor experience. AIDS Res Hum Retroviruses 1998, 14(7):561-569.

21. Silvestri G, Munoz C, Butini L, Bagnarelli P, Montroni M: Changes in CD8 cell subpopulations induced by antiretroviral therapy in human immunodeficiency virus infected patients. Viral Immunol 1997, 10(4):207-212

22. Gandhi RT, Spritzler J, Chan E, Asmuth DM, Rodriguez B, Merigan TC, Hirsch MS, Shafer RW, Robbins GK, Pollard RB: Effect of baseline- and treatment-related factors on immunologic recovery after initiation of antiretroviral therapy in HIV-1-positive subjects: results from ACTG 384. J Acquir Immune Defic Syndr 2006, 42(4):426-434.

23. Gazzola L, Tincati C, Bellistri GM, Monforte A, Marchetti G: The absence of CD4+ T cell count recovery despite receipt of virologically suppressive highly active antiretroviral therapy: clinical risk, immunological gaps, and therapeutic options. Clin Infect Dis 2009, 48(3):328-337.

24. Goicoechea M, Smith DM, Liu L, May S, Tenorio AR, Ignacio CC, Landay A, Haubrich R: Determinants of CD4+ T cell recovery during suppressive antiretroviral therapy: association of immune activation, $\mathrm{T}$ cell maturation markers, and cellular HIV-1 DNA. J Infect Dis 2006, 194(1):29-37.

25. Hunt PW, Martin JN, Sinclair E, Bredt B, Hagos E, Lampiris H, Deeks SG: T cell activation is associated with lower CD4+ T cell gains in human immunodeficiency virus-infected patients with sustained viral suppression during antiretroviral therapy. J Infect Dis 2003, 187(10):1534-1543

26. Hunt PW, Martin JN, Sinclair E, Epling L, Teague J, Jacobson MA, Tracy RP, Corey L, Deeks SG: Valganciclovir reduces T cell activation in HIV-infected individuals with incomplete CD4+ T cell recovery on antiretroviral therapy. J Infect Dis 2011, 203(10):1474-1483.

27. Valdez H, Connick E, Smith KY, Lederman MM, Bosch RJ, Kim RS, St Clair M, Kuritzkes DR, Kessler H, Fox L, et al: Limited immune restoration after 3 years' suppression of HIV-1 replication in patients with moderately advanced disease. AIDS 2002, 16(14):1859-1866.

28. Lohse N, Hansen AB, Pedersen G, Kronborg G, Gerstoft J, Sorensen HT, Vaeth $\mathrm{M}$, Obel N: Survival of persons with and without HIV infection in Denmark, 1995-2005. Ann Intern Med 2007, 146(2):87-95.

29. Ulmer A, Muller M, Bertisch-Mollenhoff B, Frietsch B: Low-dose prednisolone has a CD4-stabilizing effect in pre-treated HIV-patients during structured therapy interruptions (STI). Eur J Med Res 2005, 10(6):227-232.

30. Ulmer A, Muller M, Bertisch-Mollenhoff B, Frietsch B: Low dose prednisolone reduces $\mathrm{CD} 4+\mathrm{T}$ cell loss in therapy-naive HIV-patients without antiretroviral therapy. Eur J Med Res 2005, 10(3):105-109.

31. Andrieu JM, Lu W, Levy R: Sustained increases in CD4 cell counts in asymptomatic human immunodeficiency virus type 1-seropositive patients treated with prednisolone for 1 year. J Infect Dis 1995, 171(3):523-530.

32. Andrieu JM, Lu W: Long-term clinical, immunologic and virologic impact of glucocorticoids on the chronic phase of HIV infection. BMC Med 2004, 2:17.

33. Elliott AM, Luzze H, Quigley MA, Nakiyingi JS, Kyaligonza S, Namujju PB, Ducar C, Ellner JJ, Whitworth JA, Mugerwa R, et al: A randomized, doubleblind, placebo-controlled trial of the use of prednisolone as an adjunct to treatment in HIV-1-associated pleural tuberculosis. J Infect Dis 2004, 190(5):869-878. 
34. Hakim JG, Ternouth I, Mushangi E, Siziya S, Robertson V, Malin A: Double blind randomised placebo controlled trial of adjunctive prednisolone in the treatment of effusive tuberculous pericarditis in HIV seropositive patients. Heart 2000, 84(2):183-188.

35. McComsey GA, Whalen CC, Mawhorter SD, Asaad R, Valdez H, Patki AH, Klaumunzner J, Gopalakrishna KV, Calabrese LH, Lederman MM: Placebocontrolled trial of prednisone in advanced HIV-1 infection. AIDS 2001, 15(3):321-327.

36. Wallis RS, Kalayjian R, Jacobson JM, Fox L, Purdue L, Shikuma CM, Arakaki R, Snyder S, Coombs RW, Bosch RJ, et al: A study of the immunology, virology, and safety of prednisone in HIV-1-infected subjects with CD4 cell counts of 200 to $700 \mathrm{~mm}(-3)$. J Acquir Immune Defic Syndr 2003, 32(3):281-286.

37. Weiss L, Burgard M, Cahen YD, Chaix ML, Laureillard D, Gilquin J, Piketty C, Viard JP, Kazatchkine MD, Girard PM, et al: Immunological and virological features of HIV-infected patients with increasing CD4 cell numbers despite virological failure during protease inhibitor-based therapy. HIV Med 2002, 3(1):12-20.

38. Aiuti F, Mezzaroma I: Failure to reconstitute CD4+ T-cells despite suppression of HIV replication under HAART. AIDS Rev 2006, 8(2):88-97.

39. Massanella M, Negredo E, Perez-Alvarez N, Puig J, Ruiz-Hernandez R, Bofill M, Clotet B, Blanco J: CD4 T-cell hyperactivation and susceptibility to cell death determine poor CD4 T-cell recovery during suppressive HAART. AIDS 2010, 24(7):959-968.

40. Ryan LA, Zheng J, Brester M, Bohac D, Hahn F, Anderson J, Ratanasuwan W, Gendelman HE, Swindells S: Plasma levels of soluble CD14 and tumor necrosis factor-alpha type II receptor correlate with cognitive dysfunction during human immunodeficiency virus type 1 infection. J Infect Dis 2001, 184(6):699-706.

41. Meisner F, Neuen-Jacob E, Sopper S, Schmidt M, Schlammes S, Scheller C, Vosswinkel D, Ter Meulen V, Riederer P, Koutsilieri E: Disruption of excitatory amino acid transporters in brains of SIV-infected rhesus macaques is associated with microglia activation. J Neurochem 2008, 104(1):202-209.

42. Gonzalez-Scarano F, Martin-Garcia J: The neuropathogenesis of AIDS. Nat Rev Immunol 2005, 5(1):69-81.

\section{Pre-publication history}

The pre-publication history for this paper can be accessed here: http://www.biomedcentral.com/1471-2334/12/14/prepub

doi:10.1186/1471-2334-12-14

Cite this article as: Kasang et al:: HIV patients treated with low-dose prednisolone exhibit lower immune activation than untreated patients. BMC Infectious Diseases 2012 12:14.

\section{Submit your next manuscript to BioMed Central and take full advantage of:}

- Convenient online submission

- Thorough peer review

- No space constraints or color figure charges

- Immediate publication on acceptance

- Inclusion in PubMed, CAS, Scopus and Google Scholar

- Research which is freely available for redistribution

Submit your manuscript at www.biomedcentral.com/submit
C BioMed Central 